\title{
Innovation and Problem Solving Teaching Case: The Breakout Box - A Desktop Escape Room
}

\author{
Ron Duggins \\ University of Central Arkansas
}

This article concerns applying engactive (engaged \& active) teaching approaches such as gamification, game based learning, and experiential education to teaching innovation, critical thinking, and creative problem solving in addition to content in a unique and memorable way. The escape room industry has seen tremendous growth and the rooms are being used for team building exercises and to actively teach creative and group problem solving. Two issues with using escape rooms are the logistical and time aspects. This article describes ways a table top escape room teaching tool overcomes these issues to create an engactive learning environment.

Keywords: Innovation, Creative Thinking, Pedagogy, Engagement

\section{INTRODUCTION}

The philosopher Michael Polanyi indicates that true learning happens when we immerse ourselves in what we learn, and this is the case in utilizing gaming and experiential education. By more fully immersing students into the action of learning, rather than just the somewhat passive act of reading what we want them to learn, students become more engaged and take ownership of their knowledge. One of the ways this is occurring today is through the increase of what I call engactive learning approaches such as gamification, game based learning (GBL), play, serious play, active and experiential learning in education environments. Engactive learning is the combination of intentionally engaging and active oriented leaning processes. Engactive learning is increasing across all domains of knowledge. The tools and approaches to these types of learning are showing up in corporate environments, business schools, nursing and pharmacy schools, and library activities (Adams, et al., 2018; Eukel, et al., 2017). They are being used in the corporate environment, professional development, and kindergarten classes. In universities and colleges, instructors are seeking to present information in meaningful and engaging ways with students that have grown up with technology, video games, and in network structures.

As the growing research into engactive teaching methods shows, a high percentage of participants report they are more engaged and motivated when gamification, GBL, active learning, etc. are incorporated (Chapman \& Rich, 2018; Ceker \& Ozdamh, 2017; Patricio, Moreira, \& Zurlo, 2018; Wise et al., 2018; Faiella \& Ricciardi, 2015). Chapman and Rich (2018) emphasize the point made by Lee and Hammer (2011) that gamification seeks to engage students at a level that encourages them to "participate more deeply in their education and perhaps change their self-concept as learners" (p. 320). The goal of engactive approaches to learning is to connect more deeply with students using intentionally engaging and 
active processes for the purpose of higher engagement and retained and meaningful learning. Escape rooms are one of these tools being used today.

The escape room has aspects both of gamification and game based learning (GBL). While game based learning can be seen as learning during the process of playing or gaming, gamification utilizes game features and thinking for increasing motivation and enhancing problem solving (Bruder, 2014; Ceker \& Ozdamh, 2017; Chapman \& Rich, 2018). The escape room industry has seen strong growth in the past decade with more than 2,300 facilities in the United States alone (Spira, 2018). More than just providing a fun activity to occupy a few hours of time, escape rooms are being used for team building exercises as well as to actively teach creative and group problem solving. Two of the biggest issues with using escape rooms in teaching is the logistical and time aspects. Considering the value that can be derived from the escape room experience, but taking into consideration the logistical and time issues, an organization known as BreakoutEDU (https://www.breakoutedu.com/) has developed a table top version of the escape room. BreakoutEDU promotes this tool as a way to not only teach content, but in an engaging way get the students actively involved in effective communication and team problem solving (Bellow, 2019). The following information will highlight how the Breakout Box can be used to further extend the engactive approach of the Escape Room to an individual classroom without having to leave the building.

\section{CASE BODY}

The Breakout Box lessons are created to teach and reinforce both course content as well as engage the students in activities that require divergent, creative, and team-based thinking. The creators of the BreakoutEDU kit and Platform promote the use of a Breakout Box in the classroom as developing critical thinking, collaboration, creativity, and communication. I have found this to be true in my classroom. In order to teach and reinforce course content the instructor would develop or use a pre-developed Breakout Game that is built using the concepts, vocabulary, and ideas from the subject area. As the students seek to solve each puzzle, quiz, or discover clues, the course content can be these points of discovery. In order to discover these points the students must approach the activity utilizing high critical thinking skills, clarity of thought, divergent ideas, process of elimination, clear communication, and many other thinking processes that challenge the individual or groups working together to break into the final box.

To gain access to the BreakoutEDU resources one must purchase a membership to the BreakoutEDU Platform. Membership allows the user to access hundreds of BreakoutEDU games developed by both the BreakoutEDU organization as well as practitioners from around the world. The largest number of games are targeted to elementary school aged classrooms, but there are games for all ages with areas of course content such as Computer Science, Mathematics, Library, Science, Social Studies, Game Design, Team Development, Language Learning, Career \& Technical Education, and others. The games can be physical games that utilize the physical items listed below, but there are also games that are in digital or a hybrid digital/physical format. The digital games require the students to solve the clues online with interactive virtual locks and boxes, BreakoutEDU offers developer resources to instructors and students who want to develop their own games. In order to be considered for inclusion on the BreakoutEDU Platform the developer must use the "Official Game Template" and create an overview and instructional video using the BreakoutEDU Video Template. While the use of the BreakoutEDU platform does offer many advantages, the creation and use of this type of teaching tool can be done independently as well.

The discussion below will detail the use of the physical version of the Breakout Box. As the name implies, the activity normally utilizes a table-top sized box or boxes and other items. The box used by this professor is approximately 11 inches square and 6 inches deep. The game setup can be purchased from www.breakoutedu.com or one can obtain an open source list and gather or buy the items themselves or build, create, or repurpose items. A standard single kit from breakoutEDU.com comes with

- 1 Large Breakout EDU Locking Box - 1 Small Breakout EDU Locking Box
- 1 Four-digit lock

- 1 Key lock (with three identical keys) 
- 1 Hasp

- 1 Alphabet Multilock

- 1 Directional Multilock

- 1 Color Wheels for Multilock

- 1 Shape Wheels for Multilock

- 1 Number Wheels for Multilock

- 1 Three-digit lock
- 1 Deck of Reflection Cards

- 1 Red Lens Viewer

- 1 UV light

- 1 Invisible ink pen

- 1 USB thumb drive (blank)

- 2 Hint cards

Not all items are used for each Breakout Game, but generally if one is running a few different games throughout the semester then each of these items will be put to use at some point. While these items are the standard set, an instructor can be creative to substitute, alter, or use different types of locks and boxes and other items. It is truly limited only to the creativity and willingness of the instructor to make the changes and align the story or clues to the types of items that one wishes to use in the game. I have purchased other locks such as one utilizing emojis for the combination.

To put the Breakout Box to use in a class or session, one would select the game from the BreakoutEDU platform or develop their own game. There are guidelines to follow if one intents to submit their own game for inclusion on the BreakoutEDU Platform. For each game on the Platform there is a corresponding site that provides the Storyline, Lock Combinations, Setup Instruction with a Video Tutorial, and links to the Game Resources that are normally found in a Google Drive folder. Game resources include items such as printouts, QR codes, files to download to a flash drive, red herring clues, and others as well.

To give the reader a better understanding of how the tool is used, this following will outline the use of a Breakout Game that was initially built as a General Interest Game for high school through adult learners with content around advertising. The name of this Game is "Ad Agent" and was created by BreakoutEDU.

The "Ad Agent" game is set in the 1950's. The students are introduced to a character named G. McFly who has decided to become a spy against the United States and the students must locate and stop him. The clues to do so are built around advertising from the 1950's.

This particular setup utilizes the large Breakout Box that has the final location of G. McFly as well as a smaller lockbox with a 3-digit combination. The game starts with a few clues to get the student on the trail of G. McFly. The first goal is to break into the smaller lockbox with the 3-digit combination. In order to do this the students must discover the clues found in an initial dossier handout as well as find various clues scattered around the room. These include 1950's advertising posters for travel, QR codes, and a postcard sent from G. McFly. Once they are able to discover the 3-digit combination they open the smaller lockbox and find other clues, a flash drive, and a UV flashlight. These clues lead them to begin cracking the combination for the large Breakout Box.

The large Breakout Box is locked with a hasp that itself is secured with 4 different lock. These locks are as follows: (1) An alphabet lock that uses letters in a particular order to open; (2) A directional lock that requires the user to move the face of the lock in the correct sequence of directions (left, right, up, down); (3) A keyed padlock; (4) A 4-digit lock. The students must work together experimenting, testing, restarting, and thinking differently to piece the clues together. In this particular game the students are eventually led to a series of 1950's radio spots online as well as other game specific webpages that have hidden hyperlinks and differing imagery that they must put together correctly to learn the combinations or find the key to open all of the locks on the large Breakout Box.

The instructor can allow a certain number of hints to be given during the game to keep the momentum going. Some instructors require the students to earn the hints and other times the hint cards are offered upfront to the students. The timeframe for Ad Agent is recommended at 45 minutes. This game can be organized to pit smaller teams in the class against each other trying to find G. McFly first or given a small enough class everyone would work together on one team. Some instructors will have multiple Breakout Box sets so each team can work on their own without the instructor having to relock the boxes for the other teams once one team has successfully solved the clues. 
Once the students have broken into the box there are follow-up discussion questions to wrap up the activity. I often will have some candy, food items, or some interesting reward for breaking in first. The treat is often a bonus and not a key motivating factor. The idea of competing against other teams or being challenged to solve interesting clues has proven to be motivation enough for most students.

In addition to being an extremely engaging and different classroom activity the following are some of the ways the Breakout Box can be used in classrooms and seminars.

\section{Opening Day Activity:}

When used as the opening day activity the students are put on notice that the class will be one that will challenge them to approach learning in an active and engaged way. I use this to emphasize that learning and problem solving is a team effort and in order for the class to be as productive as possible we must all contribute. I can also begin to get a sense of how the students in the class engage a problem solving activity. I can quickly determine who will be the leaders in discussion, the followers and the divergent thinkers. The clues are often difficult and certainly require a bit of divergent thought or critical thinking and I can determine early who is comfortable with this process and which students seem to struggle. One can also teach simple lessons such as paying close attention to details as all of the information needed to complete the game is found in the game documents and links. One can build a Breakout Game around their syllabus to make sure the students have had to clearly identify the important items on the syllabus. If an instructor normally spends the first class going over the syllabus anyway, why not make it an engaging and memorable experience?

Teach Course Content:

The Breakout Games can be built around specific content. An example of this is a game named "Accounting Comes Alive" and uses accounting content. In this game the students must use concepts such as credits, debits, balance sheets, cash receipts, and others to track down an accountant that is stealing from four different banks across the county. If one were teaching the concepts of Design Thinking a game could be developed around the concepts of Empathize, Define, Ideate, Prototype, and Test. One of the digital games is built around the patent process and requires the students to dig into the aspects of previous patents in order to prove themselves worthy of receiving their own patent. This being a digital game one only needs to assign the game to a student who would work completely on a computer to solve the clues. Another interesting use of the Breakout Box would be to use it as a wrap up activity for completing a book. For example, one could develop a game around Daniel Pink's book, "A Whole New Mind" to reinforce the ideas of left and right brain thinking and the other concepts in the book.

Promote Creative and Divergent Thinking:

In order to solve successfully break into the Breakout Box. the students must exhibit the ability to break out of their fixed mindsets when it comes to problem solving. Focus, observation, and collaborative thinking are keys to discovering the way forward. The constraint of time in these activities also allows great teaching points about decision making and team work. I often see teams that do not communicate well and members are spending time trying to solve the same clues as others without a plan or knowledge of how the work is being divided. By the time most students get to the university or college classes they have mastered the "sit and get" method of education. The use of a teaching tool such as a Breakout Box pushes the students to become engactive learners and allows them to begin to engage their classmates as important to their own learning process. 


\section{CONCLUSION}

If one is hoping their students can learn to be better and more creative problems solvers and critical thinkers, why not attempt to teach these concepts in an engaging and active manner? The use of the desktop Breakout Box offers instructors and seminar leaders an easily accessible tool that incorporates the challenges and excitement of Escape Rooms but in the confines of any size room. In addition to the creative thinking skills, the opportunity to engage course content in a new and memorable way will help with the application and retention of content.

\section{REFERENCES}

Adams, V., Burger, S., Crawford, K., \& Setter, R. (2018). Can you escape? Creating and escape room to facilitate active learning. Journal for Nurses in Professional Development, 34(2), E1 - E5.

Bellow, A. (2019). Fostering collaborative problem solving in schools. Retrieved from https://www.breakoutedu.com/blog/2018/12/21/tana-ruder-case-study-blog.

Bruder, P. (2014). Game on: gamification in the classroom. Retrieved January 15, 2017, from https://www.njea.org/news-and-publications/njea-review/may-2014/gamification-in-theclassroom

Ceker, E., \& Ozdamh, F. (2017). What "gamification" is and what it's not. European Journal of Contemporary Education, 6(2), 221 - 228.

Chapman, J., \& Rich, P. (2018). Does educational gamification improve students' motivation? If so, which game elements work best? Journal of Education for Business, 93(7), 314 - 321.

Eukel, H., Frenzel, J., \& Cernusca, D. (2017). Educational gaming for pharmacy students - Design and evaluation of a diabetes-themed escape room, 81(7).

Faiella, F., \& Ricciardi M. (2015). Gamification and learning: a review of issues and research. Journal of e-Learning and Knowledge Society, 11(3), 13-21

Patricio, R., Moreira, A., \& Zurlo, F. (2018). Gamification approaches to the early stage of innovation. Creativity \& Innovation Management, 27(4), 499 - 511.

Spira, L. (2018). July 2018 Escape Room Industry Growth Study. Retrieved from https://roomescapeartist.com/2018/07/28/2018-escape-room-industry/.

Wise, H., Lowe, J., Hill, A., Barnett, L., \& Barton, C. (2018). Escape the welcome cliché: Designing educational escape rooms to enhance students' learning experience. Journal of Information Literacy, 12(1), 86 - 96. 